\title{
User Profiling Through Browser Finger Printing
}

\author{
Murad Ali, Zubair A Shaikh, Muhammad Kashif Khan, Taha Tariq \\ \{ali.murad, zubair.shaikh, kashif.khan, k102158\}@ nu.edu.pk \\ National University of Computer \& Emerging Sciences, FAST, Karachi, Pakistan.
}

\begin{abstract}
The modern world is changing rapidly. Now a day the use of internet is categorized as essentials for a common man. Everything is put on the web as it is bringing ease of access to the user. The web usage is doubled by the paradigm shift i.e. the smart phones. Online shopping has become a basic and ease of access unit of the user. Because of the huge traffic on the websites the marketing and the advertisement companies have a huge task of displaying relevant advertisements or products to users. To do this they need to track online habits of users and creating their fingerprints or a persona of the respective user. This research has different examinations on user and web-based fingerprinting. The main concept of browser fingerprinting is to gather the data even if the cookies are cleared or disabled by the user. In this paper, we examine how to track user on the basis of his/her system's profile. In this research we have extracted different hacks and exploit the browser. We have discussed that how the browser can be exploited to identify the user. The application of this work is in sales, marketing and promotions etc.

Keywords: User Profiling, User Fingerprinting, Cyber Security, User Tracking, Browser Fingerprinting
\end{abstract}

\section{RELATED WORK}

Many marketers, internet advisors and other websites use different techniques to track and identify users then to make a user persona that can be later used for advertisement and search results Another reason for user tracking is that it helps sites to know about their paid members whether the user is same or someone else is using his account. It also helps websites to know about their popular pages to increase site traffic.

The most popular and commonly used technique is to track. User these days is use of HTTP cookies or browser cookies, they are small pieces of data sent between your browser and web site according to Ayenson Wambach et al.2011, They have detected HTTP cookies on all top 100 websites. Now the problem arise for websites is that what if user delete the cookies or set the browser to reject cookies, or user is using cookie less browser, Secondly mobile phones are rapidly increasing their part in website usage, some mobile phones don't support cookies (Google has discontinued support for such mobiles). Marketers now days have also come up with a new version of tracking cookie the super cookie (also known as "the super cookie"). It's difficult to locate or delete flash cookies [1] because they are located in different portions in your system, like in any file which is being used by a Flash plugin. But the problem remains as we are depending on flash plug in, what if the user has disabled or don't have flash plug in as Wikipedia has already advising users that "It is important that super cookies [2] are blocked by browsers, due to the security holes they introduce". According to McDonald et al. $201120 \%$ of top 100 websites are using flash cookies[1], but that six of the top 100 sites had Flash cookies that were not unique. If you compare the results of Studies of Soltani 2009, McDonald 2011 and Ayenson Wambech et al.2011 it clearly show that the use of web tracking via both flash and https cookies [3] has been increased, but they all can be deleted, disabled or blocked.

To tackle this situation we have to use some other and modern tracking techniques like fingerprinting This technique helps websites to track user by looking at the characteristics or attributes of a browser like plug-ins, time zone, fonts and many other features. So users can be tracked even if they erase their cookies [2] .Many Studies and researches are going on User fingerprinting exploring the new and efficient techniques for user fingerprinting like Panoptclick, Blue Cava, Threat Metrix, Iovation Reputation Manager, they have used different attribute to make a user unique from others [4]. The Table Below shows the features used by studied Fingerprinting providers [6], features which are shaded are new or acquired through new or modified method in comparison with Panoptclick.

\begin{tabular}{|l|}
\hline Fingerprinting Category By Panapticlick \\
\hline Browser Customization \\
\hline Browser-Level User Configuration \\
\hline Browser Family and Version \\
\hline Operating System and Application \\
\hline Hardware and Network \\
\hline *TABLE [1.0] Categories of Fingerprinting by Panoptclick
\end{tabular}

Even many websites have been started implementing it according to their purpose and need. 


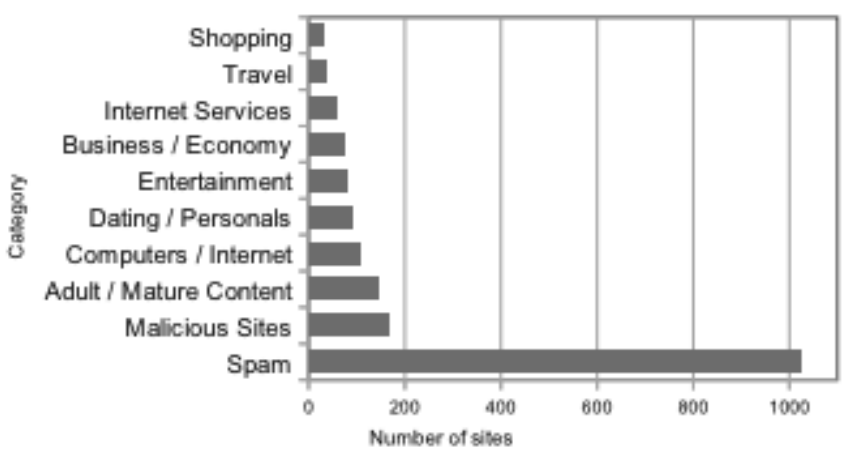

*TABLE [1.1]Top 10 categories of websites utilizing fingerprinting

According to the stats in the above figure, it clearly show that Shopping i.e. E commerce is the making the least use of fingerprinting, the most are spams, even though E-commerce can make the most out of it by identifying user and their trends.[5]

The basic key of user fingerprinting was to identifying the returning user on the same web. To detect this Eckersley (2010) formulated a simple algorithm comprising of about eight attributes of the user. Listed below:

\begin{tabular}{|c|c|c|}
\hline Variable & Source & Remarks \\
\hline User Agent & $\begin{array}{l}\text { Transmitted by HTTP, } \\
\text { logged by server }\end{array}$ & $\begin{array}{l}\text { Contains Browser micro-version, OS version, language, } \\
\text { toolbars and sometimes other information, e.g. details of } \\
\text { installed plugins. }\end{array}$ \\
\hline ACCEPT headers & $\begin{array}{l}\text { Transmitted by HTTP, } \\
\text { logged by server }\end{array}$ & \\
\hline Cookies enabled? & $\begin{array}{l}\text { Inferred in HTTP, } \\
\text { logged by server }\end{array}$ & \\
\hline Screen resolution & JavaScript AJAX post & \\
\hline Timezone & JavaScript AJAX post & \\
\hline $\begin{array}{l}\text { Browser plugins, } \\
\text { plugin versions } \\
\text { and MIME types }\end{array}$ & JavaScript $A J A X$ post & $\begin{array}{l}\text { Sorted before collection. Microsoft Internet Explorer offers no } \\
\text { way to enumerate plugins; the PluginDetect JavaScript } \\
\text { library was used to check for } 8 \text { common plugins on that } \\
\text { platform, plus extra code to estimate the Adobe Acrobat } \\
\text { Reader version }\end{array}$ \\
\hline System Fonts & $\begin{array}{l}\text { Flash applet or Java } \\
\text { applet, collected by } \\
\text { JavaScript/AJAX }\end{array}$ & $\begin{array}{l}\text { Not sorted. Note in } 200 \text { cases Mac OSX periodically } \\
\text { changed the sort order of the "Lucidia" family }\end{array}$ \\
\hline $\begin{array}{l}\text { Partial } \\
\text { supercookie test }\end{array}$ & JavaScript AJAX post & $\begin{array}{l}\text { Tests for Flash LSO cookies, Silverlight cookies, HTML } 5 \\
\text { databases and DOM globalStorage were not implemented. }\end{array}$ \\
\hline
\end{tabular}

A threshold was set for the User-agent, fonts and plugins to at most $15 \%$ to match the record if all the attributes got same. The Panopticlick project received over a million of hits and gave a result of returning users also when the browser plugin was also included to an accuracy of $99.1 \%$.

This research and algorithm was further extended by

Broenink (2012) in which he adds one different approach in which he identified the different browsers on the basis of attributes that were changed and the things that do not change. For example browser name cannot be changed but browser version can be changed like if the user updated it or the fonts installed can also get changed.

\begin{tabular}{|l|l|}
\hline Property & Assum pted Rule \\
\hline Accept & does not change \\
\hline Accept-Language & does not change (*) \\
\hline Accept-Encoding & does not change \\
\hline Accept-Charset & does not change \\
\hline Connection & does not change \\
\hline User-Agent & browser name does not change, browser version does increase \\
\hline DNT (Do Not Track) & does not change (*) \\
\hline JavaScript enabled & does not change \\
\hline JavaScript version & does not decrease \\
\hline Platform & does not change \\
\hline Charset & does not change \\
\hline Language & does not change \\
\hline Cookies Enabled & does not change (*) \\
\hline Java support & does not change \\
\hline Screen resolution & does not change (**) \\
\hline Timezone & does not change (Daylight Saving Time corrected) \\
\hline Plugin versions & do not decrease \\
\hline Font List (All) & order does not change, fonts are not removed, fonts may be added between \\
\hline \\
*TABLE [1.3] External Monitors Being Plugged in for Additional Attributes \\
\hline
\end{tabular}

K. Boda(2011) further experimented by adding some more attributes to the database. He tracked the user on the basis of IP address and through its derived attributes like locality. He further closes the user down by extracting the time-zone. The list he populated is give below.

\begin{tabular}{|l|l|}
\hline locality & Hungarian or international \\
\hline short user ID & user ID in a shorter, hashed format \\
\hline created & time of fingerprint creation \\
\hline ip & visitor IP address in a hashed format \\
\hline UAS & the user agent string of the browser \\
\hline os & operating system \\
\hline screen & screen resolution \\
\hline timezone & time zone \\
\hline basic fonts & standard font list for user ID generation \\
\hline all fonts & all detected installed font list stored for analysis \\
\hline
\end{tabular}

But the results were not that efficient enough as for instance, if the two users are using the same IP address then this algorithm made only identity of the user on the basis of the IP-address. Further, the user moved from place to place so the IP is not constant of an individual. But they found a very particular key to give the user a unique key that is the fonts. He ran a specialized query that extracted fonts installed on the OS. The results were very upright for the MAC and Android Oses but did not help for the UNIX users.

\section{APPROACHES}

Starting with the conventional data gathering of the users as previous through a website we hosted a website taha.codinghazard.com. Our main motivation was to get the returning user efficiently. The main constraint that we put was we make sure that the user was accessing our web-site through a smart phone. Because of this we had our resources limited but to extent we populated about 31 attributes on which we were identifying the users. We extracted several libraries of Java-Script such as Navigator and an API named WURFL, this API helped us in getting the data from the smart-phones. The populated list as follows. 


\begin{tabular}{|c|c|c|c|c|}
\hline VARIABLES & PANOPTCLICK & BLUE-CAVA & $\begin{array}{l}\text { THREAT- } \\
\text { MATRIX }\end{array}$ & $\begin{array}{l}\text { USER- } \\
\text { FINGERPRINTING }\end{array}$ \\
\hline PLATFORM & & & & J \\
\hline USER AGENT & J & J & J & 1 \\
\hline TIME ZONE & I & J & 1 & 1 \\
\hline COOKIES ENABLED & J & & & 1 \\
\hline SCREEN -RESOLUTION & J & J & 1 & I \\
\hline SCREEN-WIDTH & & & & 1 \\
\hline SCREEN-HEIGHT & & & & J \\
\hline SCREEN-COLOR DEPTH & & & & J \\
\hline SCREEN PIXEL DEPTH & & & & J \\
\hline BROWSERS- LANGUAGE & & J & J & J \\
\hline AGENT HEADER & & & & I \\
\hline BROWSER- CODE NAME & & & & J \\
\hline BROWSER -VERSION & & & & J \\
\hline IP ADDRESS & & & & $\sqrt{1}$ \\
\hline HOST NAME & & & & I \\
\hline CITY & & & & J \\
\hline REGION & & & & I \\
\hline COUNTRY & & & & 2 \\
\hline $\begin{array}{l}\text { LOCATION(longitude- } \\
\text { latitude) }\end{array}$ & & & & I \\
\hline $\begin{array}{l}\text { ORGANISATION(network } \\
\text { service provider) }\end{array}$ & & & & I \\
\hline DEVICE TYPE & & & & I \\
\hline BRAND & & & & J \\
\hline MODEL & & & & I \\
\hline OPERATING SYSTEM & & & & $\frac{1}{4}$ \\
\hline OS VERSION & & & & J \\
\hline FONTS & I & J & I & $\sqrt{1}$ \\
\hline PLUGIN & J & J & 1 & 1 \\
\hline HASH & & & & J \\
\hline
\end{tabular}

We built our base on several strong attributes like the fonts, plugins, screen-resolution, smart-phone model, IP address and the time-zone.

By combining all the attributes we generated a hash of that particular user. This hash comprised all the attributes that we gathered of the user. If someone accesses our web-site from a computer than we displayed a message that kindly access this web-page from your smart-phone.

We gather the accessible data from the user's smart-phone as the user hit our web-page for the first time, after this the user hits us for the second time we caught that the user is a returning one and hence we displayed the message to the user that you are a returning user.

We managed to gather a data set of about 2000 unique users. Once we had our hashes generated and the users were identified the next part we did was the profiling of user on an online-shopping website. This profile comprises of the track record of the user on the website. This profile is like a persona which leads us to personalize the website to the user for next user visit on the website. The user's click on the products and the user's searches (key words) are saved in the respective persona of that user.

So this is final working, when the user visits the site the system checks it that if the user is in our database or not if no then the user's profile is created if yes then that user's respective profile is retrieved and the web-site is personalized on the previous tracked results of the user.

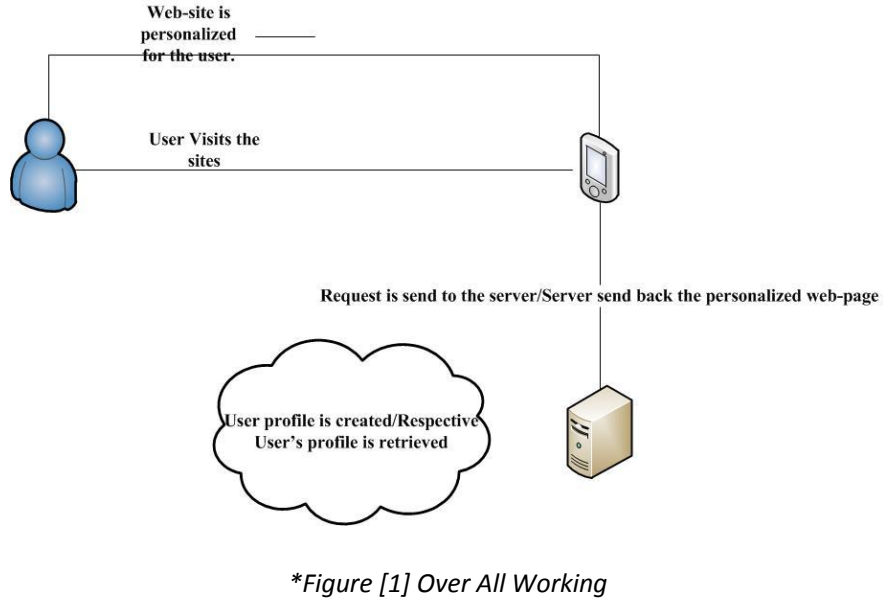

Out of 800 users $99.0 \%$ of the users were identified as returning. The key attributes for generating the hash was the IP address. If the user is on move than the IP will not be constant and for this we used a hash of the user with no IP and this hash classified the user to its respective set. On the basis of IP address several other attributes are derived such as region, country, location and organization. The big data set is broken down using this hierarchy.

The second main part of the hash was the fonts and plugins installed on the user's smart phones. But this does not help in getting the hash more unique. The fonts installed on Android, Apple and Windows devices were not been differentiated on the basis of this attribute. Because of this, results were quite low as the smart phones are rarely updated on the basis of plugins and fonts.

The screen-resolution played a little significant role in the making of the user more unique. As the smart phones have different screen sizes. Through our experiments about $20 \%$ of the users were identified by their unique screen resolutions.

The maker of the smart phones and model version combined with their operating systems running on them also made some unique input in the generation of the hash. For Android and Windows smart phones these attributes worked and contributed about $60 \%$ in the results. But Apple devices were very poor in the results not more than $10 \%$ results showed up as Apple devices were not easy to penetrate as it only showed the IOS version and the device runs on MAC. So this attribute was almost useless for the MAC devices.

The profiling part of the user has ups and downs. The user profile is a part of a set. This set contains different variations of the profile. Because of these variations the results dropped to about $60 \%$. This percentage is the systems efficiency of throwing the relevant data when the web-site is personalized per the user's persona.

\section{Methodology}

From the beginning towards the end two main prototypes were shown. The feedback was taken and recorded and also workings were done based on this. 
1) The first prototype developed in which we identified the user whether the user is new or a returning user on the basis of different attributes like fonts, time zone, location and other hacks from browser without using cookies

2) The second prototype shown included the integrated version of what was shown previously with the improve algorithm and more attributes for identification, Secondly The prototype included the profiling of user based on his history and showing him relevant content of interest on his next visit we created an ecommerce website "kapray.com "for the implementation of this prototype To test the gathered attributes it was necessary to build a platform on which we could collect the data set and to review our experiments on the attributes selected. We have to determine the results of each attribute and have to see which attribute can be modified to enhance our results.

To do all this we made up a web-site and hosted it, we started our surveys to gather the data set. We asked people to visit our website two times, so as to test our system and algorithms for the returning customers. Our system is only tolerating the access of the website through a smart phone only. After completing the system of identifying the user we created user persona in which we saved the trend and history of user so we were able to push relevant content to the returning customer next time when user visits the visit.

Figure 2 shows all the steps in the same sequence as followed.

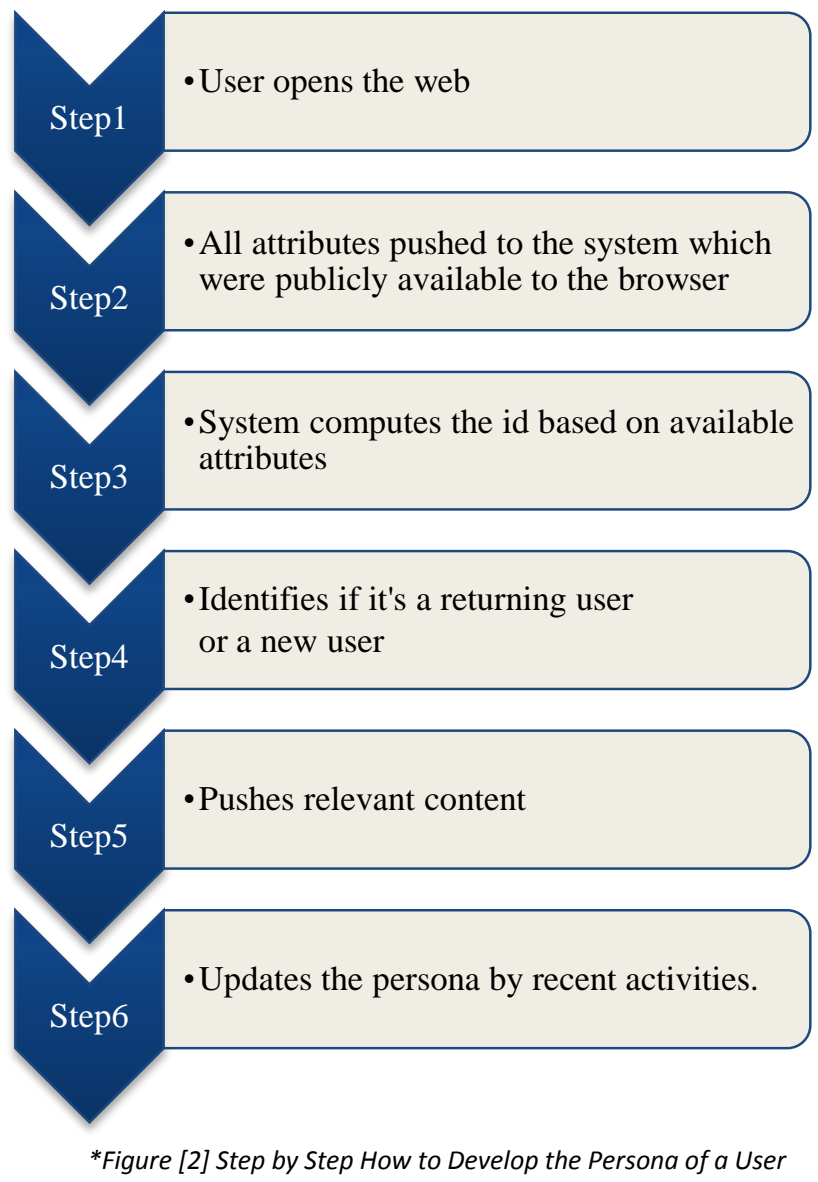

*Figure [2] Step by Step How to Develop the Persona of a User
Below is table of variables which we used to identify the user

\begin{tabular}{|l|l|l|}
\hline VARIABLES & DESCRIPTION & REFERENCE \\
\hline PLATFORM & $\begin{array}{l}\text { It tells the user platform } \\
\text { for e.g. } \\
\text { Android smart phones } \\
\text { works on Linux platform. }\end{array}$ & $\begin{array}{l}\text { Java- } \\
\text { navigator } \\
\text { library. }\end{array}$ \\
\hline USERAGENT & $\begin{array}{l}\text { Returns a string of } \\
\text { browser name and browser } \\
\text { version. }\end{array}$ & $\begin{array}{l}\text { Java- } \\
\text { navigator } \\
\text { library. }\end{array}$ \\
\hline TIMEZONE & $\begin{array}{l}\text { Tells us that in which time } \\
\text { zone of the world the user } \\
\text { lives. }\end{array}$ & Java Script. \\
\hline $\begin{array}{l}\text { COOKIES- } \\
\text { ENABLED }\end{array}$ & $\begin{array}{l}\text { Returns a string which } \\
\text { tells us that the cookies are } \\
\text { enabled or not on the } \\
\text { client Smartphone. }\end{array}$ & Java-Script. \\
\hline $\begin{array}{l}\text { SCREEN- } \\
\text { WIDTH }\end{array}$ & $\begin{array}{l}\text { Returns a value which } \\
\text { tells the screen width of } \\
\text { the smart-phone. }\end{array}$ & Java-Script. \\
\hline $\begin{array}{l}\text { SCREEN- } \\
\text { HEIGHT }\end{array}$ & $\begin{array}{l}\text { Returns screen height of } \\
\text { the smart-phone. } \\
\text { SCREEN- } \\
\text { COLOR- } \\
\text { DEPTH }\end{array}$ & Java-Script. \\
\hline
\end{tabular}

\begin{tabular}{|l|l|l|}
\hline $\begin{array}{l}\text { SCREEN- } \\
\text { PIXEL- } \\
\text { DEPTH }\end{array}$ & $\begin{array}{l}\text { Returns a value which tells } \\
\text { the screen pixel depth of the } \\
\text { smart-phone. }\end{array}$ & Java-Script. \\
\hline $\begin{array}{l}\text { BROWSERS- } \\
\text { LANGUAGE }\end{array}$ & $\begin{array}{l}\text { Tells the installed language } \\
\text { e.g.firefox-enu,firefox-enfr. }\end{array}$ & $\begin{array}{l}\text { Java- } \\
\text { navigator }\end{array}$ \\
\hline $\begin{array}{l}\text { AGENT } \\
\text { HEADER }\end{array}$ & $\begin{array}{l}\text { Used for extraction of } \\
\text { parameters. }\end{array}$ & \\
\hline $\begin{array}{l}\text { BROWSER- } \\
\text { CODE- }\end{array}$ & $\begin{array}{l}\text { Build of the browser on } \\
\text { which it is based upon. e.g. }\end{array}$ & $\begin{array}{l}\text { WURFL } \\
\text { Api. }\end{array}$ \\
\hline $\begin{array}{l}\text { BROWSER- } \\
\text { VERSION }\end{array}$ & $\begin{array}{l}\text { Returns the current browser } \\
\text { version installed. }\end{array}$ & $\begin{array}{l}\text { Agent } \\
\text { Header. }\end{array}$ \\
\hline $\begin{array}{l}\text { IP- } \\
\text { ADDRESS }\end{array}$ & $\begin{array}{l}\text { Returns the IP address of the } \\
\text { user. }\end{array}$ & $\begin{array}{l}\text { HTTP } \\
\text { HEADER. }\end{array}$ \\
\hline $\begin{array}{l}\text { HOST- } \\
\text { NAME }\end{array}$ & $\begin{array}{l}\text { Derived from IP, the host- } \\
\text { name. User's connection is } \\
\text { directly connected. }\end{array}$ & $\begin{array}{l}\text { Break } \\
\text { down from } \\
\text { IP-Address. }\end{array}$ \\
\hline CITY & $\begin{array}{l}\text { Derived from IP, returns the } \\
\text { city where the host is placed } \\
\text { physically. }\end{array}$ & $\begin{array}{l}\text { Break } \\
\text { down from } \\
\text { IP-Address. }\end{array}$ \\
\hline
\end{tabular}

$$
{ }^{*} \text { TABLE [4] }
$$

\begin{tabular}{|l|l|l|}
\hline REGION & $\begin{array}{l}\text { Derived from IP, returns } \\
\text { the region which host- } \\
\text { name covers. }\end{array}$ & $\begin{array}{l}\text { Break down } \\
\text { from IP- } \\
\text { Address. }\end{array}$ \\
\hline COUNTRY & $\begin{array}{l}\text { Derived from IP, gives the } \\
\text { country where the client is } \\
\text { situated. }\end{array}$ & $\begin{array}{l}\text { Break down } \\
\text { from IP- } \\
\text { Address. }\end{array}$ \\
\hline $\begin{array}{l}\text { LOCATION } \\
\text { (longitude- } \\
\text { latitude) }\end{array}$ & $\begin{array}{l}\text { Derived from IP, returns } \\
\text { the longitude and latitude } \\
\text { of the client. }\end{array}$ & $\begin{array}{l}\text { Break down } \\
\text { from IP- } \\
\text { Address. }\end{array}$ \\
\hline
\end{tabular}




\begin{tabular}{|l|l|l|}
\hline $\begin{array}{l}\text { ORGANISA } \\
\text { TION(networ } \\
\mathrm{k} \text { service } \\
\text { provider) }\end{array}$ & $\begin{array}{l}\text { Derived from IP, returns } \\
\text { the organization name } \\
\text { from which the user is } \\
\text { connected. }\end{array}$ & $\begin{array}{l}\text { Break down } \\
\text { from IP- } \\
\text { Address. }\end{array}$ \\
\hline $\begin{array}{l}\text { DEVICE- } \\
\text { TYPE }\end{array}$ & $\begin{array}{l}\text { Tells device type of user } \\
\text { e.g. Smartphone or a tablet. }\end{array}$ & WURFL Api. \\
\hline BRAND & $\begin{array}{l}\text { Returns the device brand } \\
\text { name the user is using. For } \\
\text { e.g. Samsung, HTC. }\end{array}$ & WURFL Api. \\
\hline MODEL & $\begin{array}{l}\text { Returns the model number } \\
\text { of the device. }\end{array}$ & WURFL Api. \\
\hline $\begin{array}{l}\text { OPERATING } \\
\text { SYSTEM }\end{array}$ & $\begin{array}{l}\text { Tells the operating system } \\
\text { is installed on the device. }\end{array}$ & $\begin{array}{l}\text { HTTP- } \\
\text { HEADER. }\end{array}$ \\
\hline
\end{tabular}

\begin{tabular}{|l|l|l|}
\hline $\begin{array}{l}\text { OS- } \\
\text { VERSION }\end{array}$ & $\begin{array}{l}\text { Returns the operating } \\
\text { system version of the } \\
\text { running OS on the device. }\end{array}$ & $\begin{array}{l}\text { HTTP- } \\
\text { HEADER. }\end{array}$ \\
\hline FONTS & $\begin{array}{l}\text { Returns the total fonts } \\
\text { installed in the browser. }\end{array}$ & Java-Script. \\
\hline PLUGINS & $\begin{array}{l}\text { Returns the plugins } \\
\text { installed in the browser. }\end{array}$ & Java-script \\
\hline HASH & $\begin{array}{l}\text { Key on which user is } \\
\text { identified. }\end{array}$ & $\begin{array}{l}\text { Self- } \\
\text { generated. }\end{array}$ \\
\hline
\end{tabular}

\section{DEPLOYMENT}

To test this research we implemented it on a distance learning system and a library management system. The results are encouraging enough so that we are working now to develop a flexible IDE based solution to work in parallel with any management system. To give a brief idea here see a scenario with the result. Figure 3.1 shows the home page when any user hits the web link for the first time. You can see various items of mix categories on home page.

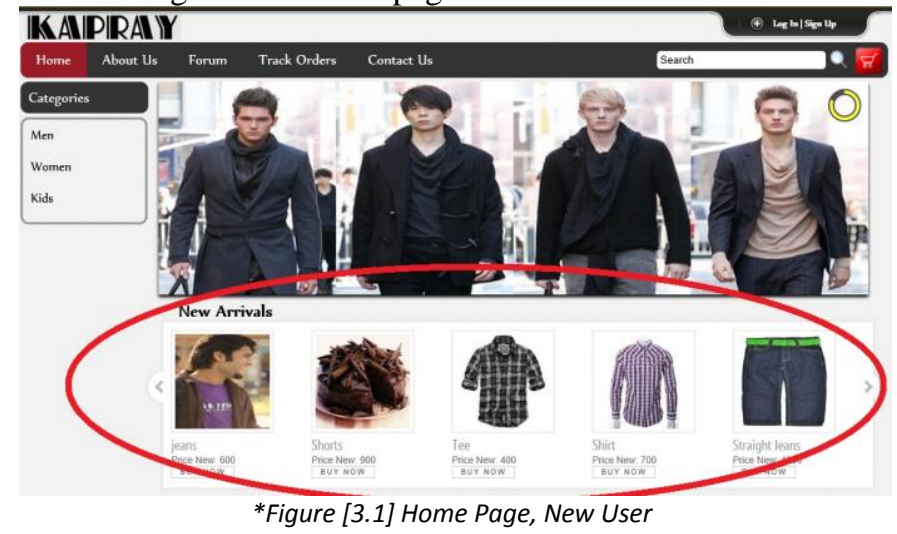

Later the user search for the red products. From the list of all red products user clicks on a particular red product.

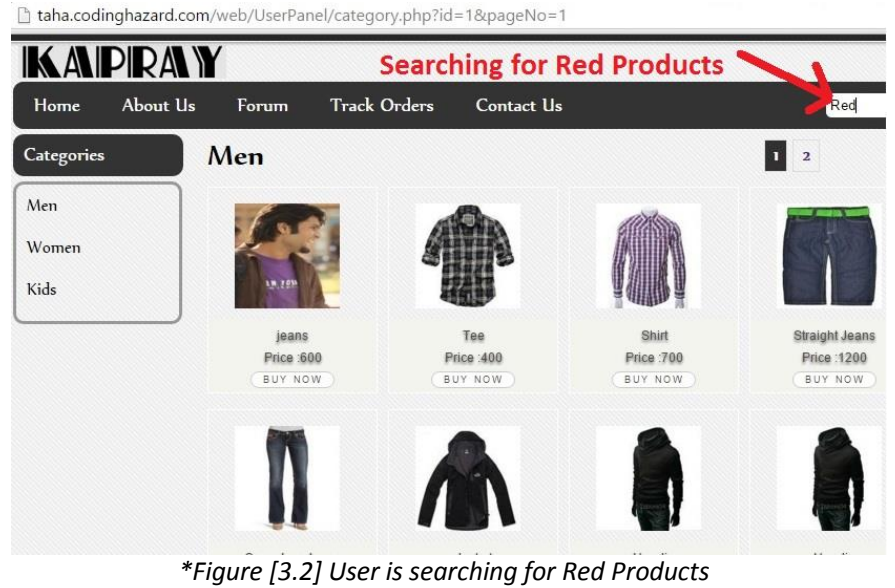

Again same user hits the home page and now the available product is showing before any other product as the system has recognized the taste of the user with the help of user finger printing. Even the user clears his/her cache but still there will be no impact on results.

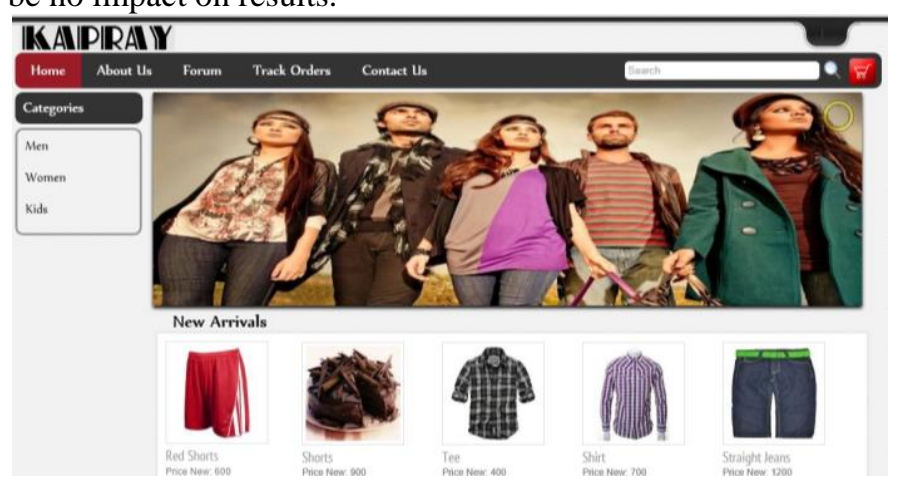

*Figure [3.3] Old User Hits Home Page and Gets His interest on Home Page

\section{FUTURE WORK}

This system will get mature as more users interact with the system. As the data set will increase more efficient results would be determined and efficient algorithms could be made. The attributes can be also increased on the basis of different hacks of the browser. User profiling could be made more reliable and efficient. This profiling will certainly help a lot in the marketing perspective of an online shopping website as well as sales of the products. This was our part of the project but we could not implement it efficiently because of the required capabilities in the time available. Our system will take time so as to learn the patterns of the user. Hence efficient algorithms of machine learning can be engineered so as to get better results.

\section{CONCLUSION}

The first objective of our research was to get as much attributes of the browser so as to identify the user more efficiently. We achieved this through our extensive research, also by the review of Panopticlick, BlueCava and Petportal.

We gathered some more attributes by using different CSS hacks and Java-Navigator library and also using WURFL API. The second objective of our research was to get the returning user identified. We were able to identify about $75 \%$ of the 
returning user the remaining $25 \%$ comprises different variables which did not helped us in the results these were fonts, plugins, IP address and Mac issues.

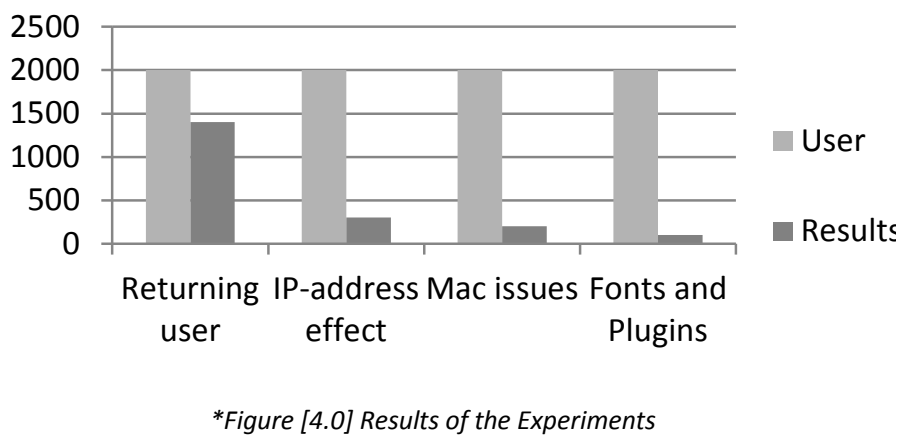

The third objective of our research was to get design a system to efficiently personalize the web-site as per the user's profile. We took two attributes of the user that is User searches the products and User clicks on the products.

\section{REFERENCES}

[1] Ashkan Soltani, Shannon Canty, Quentin Mayo, Lauren Thomas, and Chris JayHoofnagle, Flash Cookies and Privacy

[2] Ayenson Wambach et al,Flash Cookies and Privacy II: Now with HTML5 and ETag Respawning

[3] McDonald, A. M., \& Cranor, L. F., A Survey of the Use of Adobe Flash Local Shared Objects to Respawn HTTP Cookies, CMU-CyLab

[4] Eckersley, P. (2010) 'How Unique Is Your Web Browser?'

[5] Boda, K., Földes, Á., Gulyás, G. and Imre, S. (2011) 'User Tracking on the Web via Cross-Browser Fingerprinting', NordSec'11

[6] Broenink, R. (2012) 'Using Browser Properties for Fingerprinting Purposes' 